\title{
A IRREFLEXÃO E A BANALIDADE DO MAL, DO PENSAMENTO DE HANNAH ARENDT, REFLETIDOS NO EXERCÍCIO DO PODER JUDICANTE
}

\author{
THE THOUGHTLESSNESS AND THE BANALITY OF EVIL, THE THOUGHT OF \\ HANNAH ARENDT, REFLECTED IN POWER THE YEAR ADJUDICATIVE
}

Ana Carolina Pedrosa Massaro*

\section{Resumo}

O presente artigo tem por escopo analisar o exercício do Poder Judicante a partir da conceituação de Hannah Arendt sobre a irreflexão e a consequente banalidade do mal. Com efeito, pretende-se, por meio deste estudo, fazer um comparativo entre as observações Arendtianas sobre a forma irracional de simplesmente obedecer ordens e seguir um código de ética pré-determinado, sem refletir sobre a conduta tomada, levando-se à banalidade do mal descrita pela filósofa quando do julgamento de Eichmann, com as decisões proferidas pelos magistrados em geral, que muitas vezes, para aplicarem rigorosamente a lei ao caso concreto, deixam de compreender as reais necessidade das partes e os motivos que as levaram a procurar o Poder Judiciário, e não contribuem para a obtenção de Justiça, na mais escorreita acepção da palavra.

Palavras-chave: Banalidade do mal. Irreflexão. Poder judicante. Ética.

\begin{abstract}
The scope of this article is to analyze the exercise of adjudicative power from the conceptualization of Hannah Arendt on the thoughtlessness and consequent banality of evil. Indeed, it is intended, through this study, to make a comparison between the observations Arendtian on how irrational simply obey orders and follow a code of ethics predetermined, without reflecting on the outlet duct, leading to the trivialization of poorly described by the philosopher when the Eichmann trial, with decisions handed down by judges in general, often to rigorously apply the law to this case, fail to understand the real needs of the parties and the reasons that led them to seek the Judiciary and do not contribute to the attainment of justice, in more ordinary sense of the word.
\end{abstract}

Keywords: The banality of evil. Thoughtlessness. Adjudicative power. Ethics.

\section{Introdução}

Em meio aos horrores produzidos pelo Nazismo, uma filósofa do gênero feminino, alemã e judia se dedicou a estudar as motivações que levaram o pensamento

\footnotetext{
* Doutorado em curso pela Facultad de Derecho de la Universidad de Buenos Aires - Argentina, na área de Direito Civil. Especialista em Direito Processual Civil, pela FAAP - Fundação Armando Alves Penteado, e em Direito do Agronegócio, pela UNIARA. Pós-graduanda em Direito de Família, pela Faculdade de Direito Damásio de Jesus. Bacharel em Direito pela Faculdade de Direito de Franca. Realizou curso de extensão universitária na Universidade de Cambridge, na Inglaterra. Participação como conferencista em eventos e palestras jurídicas no Brasil e no exterior. É autora e coautora de livros e artigos jurídicos publicados no Brasil, na Argentina, em Portugal e na Itália. Membro do Comitê de Ética em Pesquisa com Seres Humanos da Faculdade de Ciências Farmacêuticas de Ribeirão Preto da Universidade de São Paulo (USP). Professora de Direito de Família, Bioética e Direitos Humanos. Advogada no escritório Marcussi, Jamel \& Massaro Advogados, em Ribeirão Preto/SP.
} 
humano a produzir tanta dor, sofrimento e separação. Inserido neste contexto de indignação e busca por explicações, este artigo pretende expor os pensamentos da filósofa Hannah Arendt acerca do termo banalidade do mal, fazendo-se, posteriormente, uma comparação entre a ausência da atividade de pensar e julgar, observadas por ela durante o julgamento de Eichmann - carrasco nazista e um dos grandes responsáveis pelo extermínio de judeus na Alemanha -, com a maneira pela qual são preferidas as decisão judiciais no cenário nacional.

Assim, a partir da reflexão sobre os perigos existentes em não pensar, não refletir, obedecer cegamente um código de ética pré-existente, estabelece-se neste artigo um paralelo com a atividade judiciária de "dizer" o Direito, analisando não somente a conduta dos profissionais da área, mas especialmente de que forma a ausência de pensamento, de reflexão sobre a lei que efetivamente será aplicada ao caso concreto e, sobretudo, sobre a realidade e os anseios daqueles que procuram o Poder Judiciário, levam a uma banalização do mal e com isso nega-se Justiça ao caso concreto.

\section{Hannah Arendt e a banalidade do mal}

Hannah Arendt nasceu em Hannover, na Alemanha, em 1906. De origem judia, refugiou-se nos Estados Unidos da América durante o Nazismo e acompanhou, como jornalista correspondente do jornal The New Yorker, o julgamento de um dos maiores exterminadores de judeus do século XX, o comandante do Reich, Adolf Eichmann. Em tal evento, ela teve a oportunidade de entrevistar pessoalmente o acusado e, para seu espanto, concluiu tratar-se de um ser humano irreflexível. Apesar da crueldade inimaginável de suas atitudes e de todas as atrocidades que cometeu, Eichmann mostrou-se, nos dizeres de Hannah Arendt, “ordinário, comum, nem demoníaco, nem monstruoso.,

A partir desta constatação, Hannah escreveu a obra Eichmann em Jerusalém: um relato sobre a banalidade do mal, na qual se deteve em analisar o mal que advém da ausência de reflexão sobre atos e condutas, o obedecer cegamente a um código de ética pré-determinado, sem questionar, sem pensar sobre o que está de fato fazendo. 
Esta linha de raciocínio foi duramente criticada no século $\mathrm{XX}$, pois acreditou-se que Hannah Arendt havia sido benevolente com o maior exterminador de judeus que a História conheceu, eximindo-lhe da culpa pelas barbáries cometidas, sob o pretexto de que ele de fato não saberia o que estava fazendo, pois nunca havia pensado a respeito, era um mero cumpridor de ordens.

Ocorre que as implicações morais e sociais da irreflexão apontada por Arendt não se limitavam apenas a condenar ou absolver culpados pelo Holocausto, mas, sobretudo, foi uma maneira corajosa e objetiva de entender o que realmente havia nas mentes daquelas pessoas que participaram ativamente do aniquilamento do povo judeu alemão.

Com efeito, em momento algum a filósofa isentou Eichmann de sua culpa. Pelo contrário, entendeu que todos os participantes do Reich eram culpados por seus atos, mas era necessário observar certa distinção entre os graus de responsabilidades dos líderes do movimento totalitário e da grande massa burocrática que cumpria friamente as ordens da cúpula nazista.

Baseada ainda nesta conclusão, Hannah divergiu também da então conhecida teoria da engrenagem (cog-theory), a partir da qual todos os integrantes de um sistema eram tidos como simples peças de uma grande engrenagem e, portanto, não agiam por seus próprios pensamentos, o que significaria isentá-los de culpa e responsabilidades individuais.

A filósofa jamais concordou que o não pensar implicasse em isenção de culpa, mas observou que havia um enorme abismo entre as atrocidades cometidas por Eichmann e a superficialidade reflexiva do agente responsável pelos ditos atos, o que chamou de banalidade do mal.

Hannah Arendt questionava as consequências advindas do não pensar, do não refletir, do ser guiado pelo que outros pensaram, e o fazia com o intuito não de escusar os não pensantes, mas de demonstrar que situações gravíssimas e dramáticas podem ser geradas diante da irreflexão. 
Mais do que isso, Arendt analisa profundamente em suas obras o vínculo entre pensar e agir, questionando se a simples atividade de pensar seria suficiente para evitar que uma pessoa faça o mal, ou que seja ainda determinante para que ela faça necessariamente o bem. Nestes termos, dizia ela: "Será que a natureza da atividade de pensar, o hábito de examinar, refletir sobre qualquer acontecimento, poderia condicionar as pessoas a não fazer o mal? Estará entre os atributos da atividade do pensar, em sua natureza intrínseca, a possibilidade de evitar que se faça o mal? Ou será que podemos detectar uma das expressões do mal, qual seja, o mal banal como fruto do não exercício do pensar?",

Pensar sobre as consequências do não pensar foi objeto de estudo da mencionada filósofa do século XX e, certamente, não apenas sua visão como cientista política, mas, sobretudo, como parte integrante da comunidade judia, perseguida e massacrada durante o Nazismo, foi decisiva para analisar e compreender como as atitudes advindas da irracionalidade, da irreflexão, são tão, ou mais, devastadoras que aquelas oriundas da meditação e do planejamento, uma vez que a simples associação do fenômeno do mal com a ética tinha se tornado insuficiente para explicar todo o horror e as barbáries cometidas na Alemanha durante o Nazismo.

Era o verdadeiro colapso moral e a situação exigia que se aprofundasse o raciocínio a fim de se chegar à verdadeira ligação que há entre pensar e agir. Era preciso saber se a atividade humana do pensamento está ou não ligada à conduta ética de discernir entre o certo e o errado.

Importante observação foi feita por Hannah Arendt quando trouxe à baila a expressão banalidade do mal: "por traz da expressão (banalidade do mal) não procurei sustentar nenhuma tese ou doutrina, muito embora eu estivesse consciente de que ela se opunha à nossa tradição de pensamento literário, teológico ou filosófico, sobre o fenômeno do mal’”

Assim, o que se observa é que Arendt relacionou toda a maldade e as atrocidades cometidas pelos carrascos nazistas, que simplesmente obedeciam às ordens emanadas de Hitler, à ausência de reflexão ou pensamento sobre a lei vigente à época. É R. Fac. Dir. UFG, v. 38, n. 1, p. 207-222, jan. / jun. 2014 
natural do ser humano mentalmente sadio distinguir o certo do errado, desde que reflita sobre isso, e não é preciso ser inteligente para fazê-lo. Para Hannah Arendt todo ser humano é capaz de pensar e esta teoria contrariava a posição de Kant, que acreditava que tal atributo era exclusivo dos filósofos.

Neste contexto, cumprir cegamente ordens deixa o homem refém daqueles que as estipulam e, por óbvio, retira-lhe a criticidade e, até mesmo, a autocrítica. Por tal motivo, os carrascos nazistas não tiveram conflito algum de consciência, porque jamais chegaram a questionar a realidade fática em que estavam inseridos, e foi nestes termos que Hannah Arendt, ao escrever sua obra A Vida do Espírito, discorreu sobre as duas vertentes do pensamento: os perigos existentes tanto na atividade de pensar como na ausência de pensamento, que pode levar à maldade.

A autora afirma que "há alguns anos, em relato sobre o julgamento de Eichmann em Jerusalém, mencionei a "banalidade do mal”. Não quis, com a expressão, referir-me a teoria ou doutrina de qualquer espécie, mas antes a algo bastante factual, o fenômeno dos atos maus, cometidos em proporções gigantescas atos cuja raiz não iremos encontrar em uma especial maldade, patologia ou convicção ideológica do agente; sua personalidade destacava-se unicamente por uma extraordinária superficialidade".

Neste contexto, Arendt sustentou que o mal não poderia ser explicado como uma fatalidade, mas sim caracterizado como uma possibilidade da liberdade humana. Foi assim que ela afirmou por diversas vezes que Eichmann foi um bom pai de família, um filho exemplar e um irmão dedicado, mas também foi um grande assassino, capaz das maiores crueldades e atrocidades.

O mal encontrado em Eichmann foi definido como banal por não ter explicação, motivação, ideológica, patológica ou qualquer questão demoníaca. O conceito de Hannah Arendt de mal banal se refere a um fenômeno sem inspiração própria, mas nem por isso deixa de ser assombroso em suas consequências. Havia um abismo entre a gravidade dos atos e a superficialidade das motivações que levaram Eichmann a ser o maior carrasco Nazista da História. Nestes termos, Arendt conseguiu 
apontar o ineditismo do mal efetivado pelos burocratas nazistas, que executavam ordens sem se questionar sobre o que estavam fazendo.

No pensamento elaborado por Hannah Arendt, seguir friamente um código de ética pré-determinado, fazendo-o de forma irreflexível, é capaz de produzir uma maldade sem precedentes, pelo que é preciso estimular o pensamento crítico do ser humano - independentemente do seu grau de intelectualidade e do cargo que ele ocupe -, a fim de evitar que barbáries como as que foram cometidas durante o Nazismo voltem a ocorrer.

\section{Quem foi Adolf Eichmann?}

Eichmann nasceu no mesmo ano que Hannah Arendt, 1906, no dia 19 de março, na cidade de Solingen, no norte da Alemanha e morreu enforcado em Jerusalém, na prisão de Ramleh, em 31 de maio de 1962, por ter sido condenado pelos crimes de guerra cometidos durante o Nazismo. Dentre as acusações que lhe pesavam estavam crimes contra a humanidade, crimes contra o povo judeu e de pertencer a uma organização criminosa.

No fim da Segunda Guerra Mundial, em maio de 1945, ele foi capturado por tropas americanas, mas escapou do campo de prisioneiros em que estava confinado e fugiu para a Argentina, onde constituiu uma nova identidade, passando a usar o nome de Ricardo Klement. Contudo, seus esforços foram em vão, pois, após 15 (quinze) anos de fuga, em 1960 foi capturado pelo serviço secreto israelense e levado a julgamento em Jerusalém.

Eichmann foi, no terceiro Reich, o comandante responsável por "solucionar as questões judaicas", organizando a expulsão dos judeus e, por fim, encaminhando-os para as câmaras de extermínio. Desde que ele assumiu o cargo, 45.000 (quarenta e cinco mil) judeus deixaram a Áustria e 19.000 (dezenove mil) deixaram a Alemanha, isso em apenas 8 (oito) meses. Passado um ano e meio, mais de 148.000 (cento e quarenta e oito mil) judeus haviam sido expulsos, ou seja, $60 \%$ (sessenta por cento) da população judia dos países dominados pelo nazismo. 
O comandante em voga tinha muita destreza em realizar duas importantes tarefas: negociar e organizar, pelo que teve êxito em retirar tantos judeus da Alemanha e dos países dominados pelo Nazismo, fazendo-o em tão curto espaço de tempo, e, por mais horrendo que isso possa parecer, o fez de forma "legal", ou seja, cumpriu com subserviência exemplar os comandos que lhe foram dirigidos e respeitou cada linha do código de ética adotado pelo Partido Nacional Socialista.

Todas as atitudes de Eichmann visavam a um único propósito: obter uma patente. Diz Arendt: “Com sua sincera devoção, questões de família e de carreira pessoal, era o último e já degenerado produto da crença do burguês na suma importância do interesse privado. [...] É o burguês isolado da sua própria classe, o indivíduo atomizado produzido pelo colapso da própria classe burguesa". ${ }^{4}$

A crueldade e a frieza dos atos de Eichmann podem sugerir tratar-se de um ser monstruoso, demoníaco e que calculava cuidadosamente todos os seus passos. Mais do que isso, podia-se pensar que o tal comandante fosse consciente de si e muito bem sucedido em seus intentos.

Ocorre que a verdade é diametralmente distante disso, Eichmann era, de fato, um ser irreflexível, ele não pensava por si próprio, era um mero cumpridor de leis e ordens, e buscava enquadrar-se no sistema simplesmente para ser reconhecido e congratulado. Originário de uma família de classe média, Eichmann era dotado de mediana inteligência e detentor de um discurso robotizado, sempre embasado em frases feitas, clichês e repetições de pronunciamentos alheios. Não havia nele convicção para se filiar ao partido Nacional Socialista, mas o fez sem jamais permitir se convencer por aquela ideologia.

Nunca foi dado aos estudos e desde criança se saia muito mal na escola, chegando até mesmo a abandonar o curso de engenharia no qual se matriculou. Prestava serviços ordinários na modesta empresa de mineração do seu pai e de lá saiu para empregar-se na Elekstrobau, onde permaneceu apenas por dois anos até ser demitido. 
Ironicamente, por indicação de um primo judeu de sua madrasta, Eichmann conseguiu enfim uma boa colocação em uma Cia de Óleo a vácuo, lá permanecendo por 5 (cinco) anos até ser transferido e em seguida novamente demitido.

Tratava-se, pois, de um homem fracassado, mas com ambição suficiente para lhe direcionar na busca por uma colocação profissional que lhe permitisse construir uma carreira. Tal intento foi viabilizado pelo convite do sócio de seu pai, o senhor Kaltenbrunner, em 1932, para que o então rapaz se filiasse ao Partido Nacionalista e se tornasse soldado do exército alemão.

Assim, ao filiar-se ao Nazismo, Eichmann não pretendia outra coisa senão galgar um cargo melhor do que aquele que ocupava como vendedor da Cia de óleo em comento, pois acreditava que a figura de um militar lhe traria concretas oportunidades de exercer feitos admiráveis e, quem sabe, ser congratulado com uma patente, mesmo que isso dependesse de torturar, agredir ou matar seres humanos. A crueldade de seus atos era vista por ele próprio como um mero cumprimento de ordens, não lhe gerando qualquer tipo de arrependimento ou auto reprovação.

Neste contexto, o que se observou foi que as maldades cometidas por Eichmann não eram meditadas, tampouco se tratava de um ser estúpido, que não compreendia o que estava fazendo, mas de alguém que simplesmente não tinha a capacidade de refletir sobre seus atos, não pensava.

“Quanto mais se ouvia Eichmann, mais óbvio ficava que sua incapacidade de falar estava relacionada com sua incapacidade de pensar, ou seja, de pensar do ponto de vista de outra pessoa", diz Arendt em sua obra Eichmann em Jerusalém.

Eichmann sequer chegou a ler Mein Kampf, de Adolf Hitler, e nunca demonstrou seguir a ideologia que embasou o Nazismo. Não odiava ou repudiava os judeus, mas foi um dos maiores responsáveis pelo Holocausto, sem apresentar jamais nenhum sinal de motivação para tanto. Quem chegou a conhece-lo - e aqui se inclui sua auto avaliação -, nunca o viu de outra forma senão como um cidadão correto; que seguiu as normas de conduta espelhadas no código de ética da época em que viveu; R. Fac. Dir. UFG, v. 38, n. 1, p. 207-222, jan. / jun. 2014 
cumpridor de suas obrigações e sem nenhum exagero ou fanatismo em seu comportamento cotidiano.

Arendt afirmou que "o problema com Eichmann era exatamente que muitos eram como ele, e muitos não eram pervertidos e nem sádicos, mas eram e ainda são terrivel e assustadoramente normais". E ela continua: "este era um novo tipo de criminoso, efetivamente hostis generis humani, que comete seus crimes em circunstâncias que tornam praticamente impossivel para ele saber ou sentir que está agindo de modo errado.",

Até em suas últimas palavras antes de ser enforcado, Eichmann se utilizou de clichês e frases feitas para se referir ao seu próprio funeral, demonstrando inclusive certo entusiasmo com a situação: "Dentro de pouco tempo, senhores, iremos encontrarnos de novo. Esse é o destino de todos os homens. Viva a Alemanha, viva a Argentina, viva a Áustria. Não as esquecerei.",

Arendt se vale deste momento para sintetizar toda sua lição sobre a banalidade do mal, pois este foi senão o ápice da irreflexão de Eichmann. Diz ela: "Diante da morte encontrou o clichê usado na oratória fúnebre. No cadafalso, sua memória lhe aplicou um último golpe: ele estava 'animado', esqueceu-se de que aquele era seu próprio funeral. Foi como se naqueles últimos minutos estivesse resumindo a lição que este longo curso de maldade humana nos ensinou - a lição da temível banalidade do mal, que desafia as palavras e os pensamentos." 8

\section{A banalidade do mal no poder judiciante}

Após analisar e demonstrar toda a maléfica consequência advinda da irreflexão e da ausência de pensamento, faz-se salutar observar que tais condutas podem ser cotidianamente verificadas. No mundo contemporâneo o homem tutelado, guiado, subjugado é aquele submisso e vítima dos sistemas, que determinam o que o indivíduo deve consumir, o que deve fazer, como deve se portar, etc. São estes sistemas que ditam o "certo" e o "errado". Por outro lado, o homem esclarecido é aquele que tem o poder de decidir por si mesmo, sabe o que ele quer e consegue distinguir o que para ele é certo e o que para ele é errado. 
Tal alienação e irreflexão não são somente percebidas nos cidadão comuns, como também o são nos detentores do Poder Judicante, os Juízes. Com efeito, é possível questionar-se: o magistrado tem exercido a atividade de pensar ao proferir suas decisões? A reflexão faz parte de seu trabalho, de sua rotina? Ou o pensar é apenas para os filósofos? Ou ainda, será que simplesmente aplicar a lei ao caso concreto é suficiente para realização de seu trabalho? Os cidadãos que batem às portas do Poder Judiciário não necessitam mais do que isso? E mais, será que os magistrados têm provocado maldades ao não refletirem acerca das decisões que proferem? A Justiça está realmente sendo feita?

Neste diapasão, é necessário se atentar para o fato de que a incapacidade de refletir sobre a lei, ou a aceitação pura e simples da norma positiva, inviabiliza, como aconteceu na Alemanha nazista, a efetiva realização da Justiça, que é o fim maior e mais digno do Direito. Por esta razão, o cumprimento da lei nunca pode estar desacompanhado do raciocínio sobre o certo e o errado. O intérprete da lei e, sobretudo, aquele que tem por função aplica-la, ou seja, o magistrado, jamais pode se distanciar do senso de Justiça - ainda que isso signifique agir contra a norma -, sob pena de agir contra o Direito.

Montesquieu, o grande criador da separação dos poderes, foi incisivo em consignar que "os juízes de uma nação não são, como dissemos, mais que a boca que pronuncia as sentenças da lei, seres inanimados que não podem moderar nem sua força nem seu rigor". 9

Entretanto, antes mesmo da incorporação do positivismo no Direito, Tocqueville observa que o Judiciário tem como principal atribuição ser árbitro. Todavia, o Autor consigna que para julgar um processo, o juiz primeiramente necessita julgar a lei, fazendo-o, por óbvio, dentro dos limites do próprio processo.

Neste ponto, Tocqueville amplia e transforma por completo a posição ocupada pelo juiz na relação com a própria lei. O magistrado não apenas obedece à lei, ele a julga em um processo. Assim, nos dizeres do Autor, a construção da lei não ocorre 
somente no Poder Legislativo, ela se concretiza e se perfaz especialmente no âmbito do Judiciário.

É a partir desta visão que o magistrado deveria se inserir no Poder Estatal de aplicar as leis, que é próprio da sua função. Todavia, o que se tem observado são juízes extremamente positivistas e cada vez mais alheios aos anseios e necessidades do cidadão comum, que busca no Judiciário o alento para seus sofrimentos e a mais límpida expressão da Justiça.

Fala-se aqui de pessoas comuns, modestas, trabalhadoras e cumpridoras de suas obrigações, que representam maciçamente a população e que batem às portas do Judiciário em busca de respostas para os mais diversos problemas. O que é fazer Justiça senão atender a este anseio em tempo hábil? Receber a Justiça de forma tardia é o mesmo que nunca tê-la tido.

De toda forma, aparentemente despreocupados com o real dever de seus cargos, os Magistrados, em alto grau de fidelidade e consentimento, aplicam a norma ao caso concreto e fecham os olhos para o contexto fático em que as partes estão inseridas.

Assim como Eichmann, os magistrados a que se faz referência neste trabalho são profissionais que conhecem com precisão a norma e se veem como exemplares profissionais, pois obedecem ao código de ética que lhes é ditado.

A ascensão de suas carreiras, a promoção, os títulos e honrarias se tornam mais importantes que a própria função em si, sendo que a partir do objetivo de crescer profissionalmente, muitos magistrados simplesmente ignoram a relevância da função social do Poder Judicante e passam a aplicar friamente a lei, sem refletir, sem questionar, sem pensar sobre o que de fato está sendo feito.

Em especial no Direito de Família, a realidade fática e as mudanças sociais são determinantes para definir direitos e deveres, ainda que eles não estejam expressamente escritos em Leis. Atualmente, no Brasil, discute-se com afinco sobre os direitos das minorias, alvo da exclusão social. Assim, a dignidade da pessoa humana passou a ser ponto fulcral para a nova conceituação de família, já que novos núcleos se R. Fac. Dir. UFG, v. 38, n. 1, p. 207-222, jan. / jun. 2014 
formaram e antigos paradigmas foram substituídos pela figura da sócioafetividade e do amor.

A jurista brasileira, Maria Berenice Dias, ressalta: "é necessário adequar a justiça à vida e não engessar a vida dentro de normas jurídicas, muitas vezes editadas olhando para o passado na tentativa de reprimir o livre exercício da liberdade. $O$

218 direito de família lida com gente, gente dotada de sentimentos, movida por medos e inseguranças, que sofre desencantos e frustrações e busca no Judiciário ouvidos a seus reclamos"

As famílias são compostas por pessoas que se unem unicamente por laços afetivos, que muitas vezes sobrepõem até mesmo os laços de sangue. O parentesco biológico passou a ser preterido em favor da sócioafetividade, chegando-se até mesmo à tese de que a verdadeira mãe é aquela que adota afetuosamente o seu filho. Neste contexto, o princípio da solidariedade passou a ser ponto fulcral do Direito de Família.

“O mais importante nessa viragem rumo ao princípio jurídico da solidariedade, é a compreensão de que a solidariedade não é apenas dever positivo do Estado, na realização das políticas públicas, mas também que importa deveres recíprocos entre as pessoas, pois, como disse Bourgeois, os homens já nascem devedores da associação humana e são obrigados uns com os outros pelo objetivo comum. A imposição de solidariedade levou ao desenvolvimento da função social dos direitos subjetivos, inclusive a propriedade e o contrato, que se tornou lugar comum neste início de século XXI. Sem a solidariedade, a subjetividade jurídica e a ordem jurídica convencional estão fadadas a constituírem mera forma de conexão de indivíduos que permanecem juntos, mas isolados" $" 11$

Neste novo panorama, os relacionamentos homoafetivos também ganharam proteção social e aos poucos a norma escrita foi compelida a igualar direitos e deveres que antes só conferia aos heterossexuais.

Neste cenário, os magistrados tiveram que repensar valores, tanto pessoais quanto jurídicos, pois já não cabia nenhum tipo de preconceito no exercício do Poder R. Fac. Dir. UFG, v. 38, n. 1, p. 207-222, jan. / jun. 2014 
Judicante. Ocorre que muitos deles fogem de suas responsabilidades sociais e, ao aplicarem friamente as leis, geram grandes sofrimentos, separam famílias, perpetuam discriminações e banalizam o mal, na conceituação mais ampla pretendida por Hannah Arendt.

Nos dizeres do antropólogo Leonardo Boff: "Nada mais violento que impedir o ser humano de se relacionar com a natureza, com seus semelhantes, com os mais próximos e queridos, consigo mesmo e com Deus. Significa reduzi-lo a um objeto inanimado e morto. Pela participação, ele se torna responsável pelo outro e con-cria continuamente o mundo, como um jogo de relações, como permanente dialogação."12

Tal qual Eichmann foi para o Nazismo, os magistrados detêm status perante a sociedade e representam um inigualável poder de decisão, poder este que influencia diretamente as vidas dos cidadãos, pelo que suas sentenças, por mais inofensivas que possam parecer, se não forem refletidas e pensadas, questionando-se inclusive a lei que possivelmente será aplicada ao caso concreto, são capazes de produzir um mal abominável e indizivelmente destrutivo.

Na medida em que o Poder Judicante visa unicamente garantir a pacificação social e fazer Justiça ao caso concreto, sendo a ramificação do Poder Estatal que atinge de forma mais direta os indivíduos, indubitavelmente ele deve se encarregar de uma responsabilidade diferenciada.

Alcançar uma Justiça mais rente à realidade social, mais sensível, mais retributiva e menos punitiva, só é possível quando os aplicadores da lei passam a refletir sobre o que é jurisdição e sobre a necessidade de realmente pensar sobre aquilo que está sendo ofertado à sociedade. As decisões que simplesmente obedecem leis quase nunca atendem aos anseios dos cidadãos e por esta razão negam Justiça ao caso concreto.

\section{Conclusão}

A proposta deste artigo foi realizar uma efetiva comparação entre a irreflexão e a consequente banalidade do mal, expostos pela filósofa Hannah Arendt, com o exercício do Poder Judicante, a fim de demonstrar que decisões proferidas por 
magistrados que não refletiram sobre a lei que será aplicada ao caso concreto, tampouco verificaram as reais necessidades dos litigantes, estão fadadas a obstaculizar a Justiça, pois não garantem a satisfação dos anseios do cidadão e da sociedade de forma geral.

No decorrer do levantamento bibliográfico pode-se perceber que o Direito não é apenas um conjunto de normas esboçadas em uma codificação, mas é, sobretudo, o atendimento concreto das necessidades de cada indivíduo, dentro dos limites impostos pela própria prática da vida em sociedade.

Assim, no pensamento elaborado por Hannah Arendt, seguir friamente um código de ética pré-determinado, fazendo-o de forma irreflexível, é capaz de produzir uma maldade sem precedentes, pelo que é preciso estimular o pensamento crítico do ser humano - independentemente do seu grau de intelectualidade e do cargo que ele ocupe -, a fim de evitar que barbáries como as que foram cometidas durante o Nazismo voltem a ocorrer.

Neste contexto, todas as decisões que emanam do exercício da jurisdição interferem imediatamente na vida de um e de todos e por isso os magistrados devem estar atentos, mais à sua responsabilidade pessoal, que às leis que devem ser seguidas. Isso significa que a atividade do pensamento, de julgar, da submissão dos fatos aos juízos, deve ser constante. Ao magistrado não cabe somente proferir decisões, supostamente, baseadas em normas, porque elas próprias podem levar a uma banalidade do mal. Pensar, refletir observar as reais necessidades das pessoas e as constantes mudanças sociais, não deve ser atividade somente para filósofos, sociólogos, teólogos ou antropólogos. A atividade de pensar, como Arendt assume, não é um privilégio de poucos, mas uma faculdade humana e que todos os seres humanos devem exercer. Quanto mais os magistrados.

\section{Referencias}

ARENDT, Hannah. A condição humana. Rio de Janeiro: Editora Forense; 2007.

ARENDT, Hannah. A vida do espírito. Rio de Janeiro (RJ): Civilização Brasileira: 2009. 
ARENDT, Hannah. A Condição Humana. Tradução de Roberto Raposo. 10. Ed. Rio de Janeiro: Forense, 2001.

ARENDT, Hannah. Compreender: formação, exílio e totalitarismo. Belo Horizonte (BH): Companhia das Letras/Editora UFMG; 2008.

ARENDT, Hannah. Homens em tempos sombrios. São Paulo: Companhia de Bolso; 2008.

ARENDT, Hannah. Origens do totalitarismo. São Paulo: Companhia das Letras; 1998.

ARENDT, Hannah. Sobre a violência. Rio de Janeiro: Civilização Brasileira; 2009.

ARENDT, Hannah. Eichmann em Jerusalém. Um relato sobre a banalidade do mal. Tradução de José Rubens Siqueira. São Paulo: Companhia das Letras, 1999A.

BIGNOTTO, Newton. \& MORAES, Eduardo Jardim. Hannah Arendt - diálogos, reflexões e memórias. Belo Horizonte: UFMG, 2003, p.138.

CHAVES, Rosângela. A capacidade de julgar. Um diálogo com Hannah Arendt. Goiânia. Canone Editorial, 2009.

DIAS, Maria Berenice. Manual de direito de família. 8 ed.rev. e atual. - São Paulo: Editora Revista dos Tribunais, 2011.

FERRY L. Kant: uma leitura das três “Críticas”. Rio de Janeiro: DIFEL; 2009.

LÔBO, Paulo Luiz Netto. "Conferência Magna - Princípio da Solidariedade Familiar.", Família e Solidariedade - Teoria e Prática do Direito de Família, Cunha Pereira, organizador. - Rio de Janeiro: IBDFAM - Lumen Juris, 2008.

MATOS OC. O Storyteller e o Flâneur: Hannah Arendt e Walter Benjamim. In: Moraes EJ, Bignotto N. Belo Horizonte (BH): Companhia das Letras/Editora UFMG; 2003.

MONTESQUIEU. O Espírito das Leis. São Paulo: Ed. Abril, 1973.

OLIVEIRA, Pedro A. Ribeiro. Fé e Política: fundamentos. São Paulo: Idéias e Letras, 2005

SOUKI N. Hannah Arendt e a banalidade do mal. Belo Horizonte (BH): Editora UFMG; 1998.

TOCQUEVILlE, Alexis de. A democracia na América. São Paulo: Ed. Martins Fontes, 1998. [1835]

\footnotetext{
${ }^{1}$ BIGNOTTO, Newton. \& MORAES, Eduardo Jardim. Hannah Arendt - diálogos, reflexões e memórias. Belo Horizonte: UFMG, 2003, p.138.

${ }^{2}$ Arendt H. A vida do espírito. Rio de Janeiro (RJ): Civilização Brasileira: 2009.

${ }^{3}$ Souki, Nádia. Hannah Arendt e a banalidade do mal. Belo Horizonte (BH): Editora UFMG; 1998

${ }^{4}$ Arendt, Hannah. Origens do totalitarismo. São Paulo: Companhia das Letras; 1998, pág. 388
} 
${ }^{5}$ Arendt, Hannah. Eichmann em Jerusalém: um relato sobre a banalidade do mal. São Paulo: Companhia das Letras; 1999

${ }^{6}$ Arendt, Hannah. Ibidem.

${ }^{7}$ Arendt, Hannah. Ibidem

${ }^{8}$ Arendt, Hannah. Ibidem

${ }^{9}$ MONTESQUIEU. O Espírito das Leis. São Paulo: Ed. Abril, 1973.

${ }^{10}$ Dias, Maria Berenice. Manual de direito de família. 8 ed.rev. e atual. - São Paulo: Editora Revista dos Tribunais, 2011.

${ }^{11}$ Lôbo, Paulo Luiz Netto. "Conferência Magna - Princípio da Solidariedade Familiar.”, Família e Solidariedade - Teoria e Prática do Direito de Família, Cunha Pereira, organizador. - Rio de Janeiro: IBDFAM - Lumen Juris, 2008.

${ }^{12}$ Oliveira, Pedro A. Ribeiro. Fé e Política: fundamentos. São Paulo: Idéias e Letras, 2005 